\title{
Baseline Predictors of Adherence to Positive Airway Pressure Therapy for Sleep Apnea: A 10-Year Single-Center Observational Cohort Study
}

\author{
Otto D. Schoch Florent Baty Jolanda Niedermann Jochen J. Rüdiger \\ Martin H. Brutsche \\ Division of Pneumology and Multidisciplinary Center for Sleep Medicine, Kantonsspital St. Gallen, St.Gallen, Switzerland
}

\section{Key Words}

Continuous positive airway pressure - Multivariate analysis · Patient compliance · Sleep apnea syndromes .

Quality of care

\begin{abstract}
Background: Positive airway pressure (PAP) therapy is the standard treatment for obstructive sleep apnea syndrome (OSAS). Objectives: The aim of the current study was to determine operational long-term adherence to PAP and its predictors. Methods: In a retrospective single-center observational cohort study, we analyzed all patients referred to our center with suspected OSAS between November 2001 and November 2011. Baseline results and last follow-up data of each patient were analyzed. Kaplan-Meier estimates of adherence and Cox proportional hazard regression for age, gender, Epworth sleepiness scale (ESS) scores, body mass index, apnea-hypopnea index (AHI) and oxygen desaturation index (ODI) were performed. Evolution of adherence was analyzed in yearly cohorts comparing the proportion of patients discontinuing PAP within 6 and 12 months. Results: Of 4,638 referrals, 2,187 confirmed OSAS patients started PAP, 297 (14\%) were referred out to other centers to follow-up, 42 (2\%) died, and 92 (5\%) no longer needed PAP. Of 1,756 patients, the median follow-up was 36 months [95\% confidence interval $(\mathrm{Cl}) 33.6-37.8]$, and adherence at 1, 5 and 10 years was $74(\mathrm{Cl} 71-75 ; \mathrm{n}=1,028), 55(\mathrm{Cl} 53-58 ; \mathrm{n}=281)$ and
\end{abstract}

$51 \%(\mathrm{Cl} 48-55 ; \mathrm{n}=10)$, respectively. Adherence is associated with ESS score [hazard ratio (HR) 0.60; Cl 0.47-0.78], ODI (HR $0.50 ; \mathrm{Cl} 0.32-0.77$ ) and $\mathrm{AHI}$ (HR 0.56; $\mathrm{Cl} 0.37-0.85$ ). In yearly cohorts according to inclusion date, the absconder rate at 6 and 12 months was $20(\mathrm{Cl} 18-22)$ and $27 \%(\mathrm{Cl} 25-30)$ for the first 8 years and improved to $10(\mathrm{Cl} 7-15)$ and $14 \%(\mathrm{Cl} 10-19)$ for the last 2 years, respectively. Conclusions: Long-term adherence to PAP in OSAS is associated with baseline measures of disease severity. After 2009, an improvement in the adherence rate was observed.

(c) 2013 S. Karger AG, Basel

\section{Introduction}

Obstructive sleep apnea syndrome (OSAS) is a prevalent sleep disorder, estimated to affect $4 \%$ of middle-aged men and $2 \%$ of women [1]. The main symptom of OSAS is increased daytime sleep propensity. OSAS is associated with road traffic accidents [2], arterial hypertension and metabolic syndrome $[3,4]$. Untreated OSAS is associated with increased cardiovascular morbidity and mortality [5].

Parts of the results were presented in abstract form at the Annual Conference of the European Respiratory Society in Vienna, Austria, 1-5 September 2012 (poster discussion session 77, P441).

\section{KARGER}

E-Mail karger@karger.com

www.karger.com/res
(C) 2013 S. Karger AG, Basel

0025-7931/13/0872-0121\$38.00/0
Otto D. Schoch, MD, FCCP

Division of Pneumology and Multidisciplinary Center for Sleep Medicine Kantonsspital St. Gallen, Lindenstrasse 32

CH-9007 St. Gallen (Switzerland)

E-Mail otto.schoch@ kssg.ch 
The standard treatment for OSAS, continuous positive airway pressure (PAP) applied via a nasal or facial mask [6-8], has been shown to normalize sleep and breathing. Regularly used PAP normalizes daytime functioning [2,9], improves metabolic syndrome and arterial hypertension [3], and reverses excess morbidity and mortality [5].

One major challenge in OSAS treatment programs is the education of patients in PAP use. A systematic review of 17 published studies on cognitive behavioral interventions to improve PAP usage concluded that after 4-12 weeks, in the control groups, only $15 \%$ adhered to PAP, compared to $46 \%$ [ $95 \%$ confidence interval (CI) 68-25] in the cognitive behavior groups [10]. On the other hand, $63 \%$ adherence after 13 months in 303 patients [11], 68\% after 5 years in 1,155 patients [12] and $81 \%$ in 639 patients after 5 years were reported [13] in single-center studies.

We systematically analyzed OSAS patients, diagnosed over a 10-year period at Kantonsspital St.Gallen, St. Gallen, Switzerland, to determine the quality of our routine practice over several years and to analyze the data for potential predictors of PAP adherence.

\section{Setting, Patients and Methods}

At Kantonsspital St. Gallen, a tertiary hospital in Eastern Switzerland, a multidisciplinary sleep center, led by the Pneumology Division, opened in 2001. Referrals with suspected OSAS filled out the Epworth sleepiness scale (ESS) form [14] and were assessed by a sleep specialist. If indicated, a fully supervised in-house polysomnography (PSG) recording was performed with a commercially available monitoring system [Mepal, MAP Medizin-Technologie, Martinsried, Germany (2001-2006); Embla S7000 with Rembrandt software, ResMed Schweiz AG, Basel, Switzerland (2006-2011)]. Respiration was traced with nasal pressure prongs and by piezoelectric thoracic and abdominal effort bands (20012006) or by inductance plethysmographic tracings (2006-2011). Outcome variables for the diagnosis of OSAS were the apnea-hypopnea index (AHI) and the oxygen desaturation index (ODI). The AHI was defined as the number of apneas $(>80 \%$ reduction in the flow signal for $>10 \mathrm{~s}$ ) and hypopneas ( $>50 \%$ reduction in the flow signal for $>10 \mathrm{~s}$, followed by a desaturation of $\geq 4 \%$ or an arousal) per hour of sleep. Depending on clinical complaints, symptomatic patients with an AHI of $>5$ events/h of sleep were advised to use PAP.

PAP instruction was performed in an inpatient setting by an experienced nurse. One to 5 patients arrived for an explanatory 1-hour session, repeating the pathophysiological principles of OSAS, followed by $2 \mathrm{~h}$ of testing the mask and PAP in bed. In the first night, nocturnal pulse oximetry $\left(\mathrm{SpO}_{2}\right)$ and automated PAP titration (Sullivan Autoset T) were applied. The nurses of the sleep center went on an hourly round to check if patients felt well and optimized mask fitting if necessary. For the following period, a fixed pressure or an automated PAP pressure range was chosen at the discretion of the sleep specialist. After 2-3 overnight stays, patients were discharged for home PAP. The PAP device was rented from the Swiss Lung Association (SLA), covered by mandatory health insurances. Patients were instructed to use PAP regularly, whenever they sleep.

The SLA was in charge of the technical PAP device function and performed readouts of information on objective PAP use, leakage and the persistent AHI. The SLA regularly assessed adherence and offered available features possibly improving adherence, in cases where the hours of PAP use were unsatisfactory, e.g., autoCPAP setting, expiratory pressure release functions, full face masks, nasal decongestions, sleeping pills, and others. During the first year, a consultation at the SLA office was performed at least 1 and 6-8 months after treatment start and once yearly thereafter. The retrieved information was sent to the sleep center, together with $\mathrm{SpO}_{2}$ results during PAP usage. The sleep specialist at the center analyzed the information and decided if a physician consultation was necessary.

We used our electronic patient chart system (Phoenix ${ }^{\circledR}$ ) and exported all patients with contact at the Pulmonary Division of the sleep center between November 2001 and November 2011. All paper charts were screened manually and anonymized information was entered in an ACCESS database: demographic information, ESS score and PSG results. For follow-up data, information of the last contact with the SLA or the sleep center with readouts of the PAP device and results of a pulse oximetry were entered. Patients were counted as PAP users if they were using PAP for at least 1-2 h/night and were willing to continue PAP. Patients not using or not willing to use PAP had to return the device to the SLA and were counted as PAP absconders at the time they left the device at the SLA. For patients no longer using PAP, the reason for withdrawal was collected, if available.

Statistical analyses were performed with $\mathrm{R}$ statistical software (version 2.9.0). Data are expressed as medians and interquartile ranges (IQRs). The primary dependent variable of interest was the continued use of PAP. Continuous variables are presented in the quartiles of their distribution. We modeled the risk of loss of adherence with Kaplan-Meier estimates. The median follow-up time was determined using the reverse Kaplan-Meier estimator. To identify potential predictors, multivariate Cox proportional hazard regression was performed on the quartiles as well as on the continuous variables age, gender, ESS score, AHI and ODI at baseline. The evolution of the rate of PAP adherence over time was analyzed by comparing annual patient cohorts looking at the percentage of patients discontinuing PAP within the first year with Pearson's $\chi^{2}$ test, adjusted for disease severity (AHI, ODI) using logistic regression.

The study was approved by the ethics committee of St. Gallen, Switzerland (EKSG 13/036).

\section{Results}

PAP treatment was started in 2,187 polysomnographically confirmed OSAS patients, and follow-up information was available for 1,890 patients (fig. 1). Excluded from analysis were 42 patients known to have died while 
using PAP and 92 (5\%) patients no longer in need of PAP because they lost weight $(47,2.5 \%)$, used an intraoral appliance $(40,2 \%)$ or were cured from OSAS after surgical intervention of the upper airways (5, 0.3\%). Baseline demographic data and PSG results of the remaining patients are summarized in table 1 . The median follow-up time was 36.0 months (95\% CI 33.6-37.8). The observed overall PAP adherence in 1,756 patients was $73 \%$ (CI 71-75; $\mathrm{n}=1,028)$ at 1 year, $55 \%(\mathrm{CI} 53-58 ; \mathrm{n}=281)$ at 5 years and $51 \%(\mathrm{CI} 48-55 ; \mathrm{n}=10)$ at 10 years (fig. 2 ).

At the last follow-up visit of 1,113 patients on PAP (table 2), 1,026 (92\%) were treated with CPAP, 474 (43\%) were on a fixed pressure and $552(50 \%)$ on automated pressure settings. The applied mean pressure was very similar in both treatment modes, with a median value of 9 and $9.4 \mathrm{hPa}$, respectively. The proportion of OSAS patients who had switched to noninvasive ventilation or to adaptive servoventilation because of hypoventilation or complex sleep apnea was $8 \%(\mathrm{n}=87)$. The average usage of PAP was $6 \mathrm{~h}$ (IQR 4.3-7.1), with 19\% using the device for $<4 \mathrm{~h}$ and $5 \%$ for $<2 \mathrm{~h} /$ night, respectively. Nocturnal home pulse oximetry confirmed well-controlled OSA with a median saturation of $94 \%$, a median ODI of 3 events/h and a saturation of $<90 \%$ at $<1 \%$ of the time, all within normal range (table 2). During PAP treatment, an ODI of $5-10 / \mathrm{h}$ was observed in $13 \%$ and an ODI of $>10 / \mathrm{h}$ in $11 \%$ of patients. PAP users were split according to the quartiles of PAP use per night (table 2). Older patients tended to use PAP longer. A correlation between longer PAP use and follow-up ESS scores, with significantly lower median scores for patients using PAP for more hours per night on average, was observed (table 2).

\section{Predictors of Adherence}

For 1,395 OSAS patients with complete datasets, demographic characteristics and potential predictors of PAP discontinuation are shown in table 3. In the multivariate model, correcting the relative risk for other variables potentially predicting adherence, the adjusted hazard ratio (HR) with the $95 \%$ CI for the risk to stop PAP is displayed. The ODI was a significant independent predictor of PAP adherence, with an increase in adherence for higher ODIs. The quartiles of ESS have nonlinear HR reduction with the lowest likelihood for stopping PAP in patients with a score of 11-14, while scores of $>14$ are associated with a relatively higher probability to stop PAP. Other significant independent predictors of adherence were overweight, with a body mass index (BMI) between 27.4 and 30.5 and a very high AHI of $>66$ events/h (table 3; fig. 3).

Adherence to PAP for OSAS: 10-Year Results

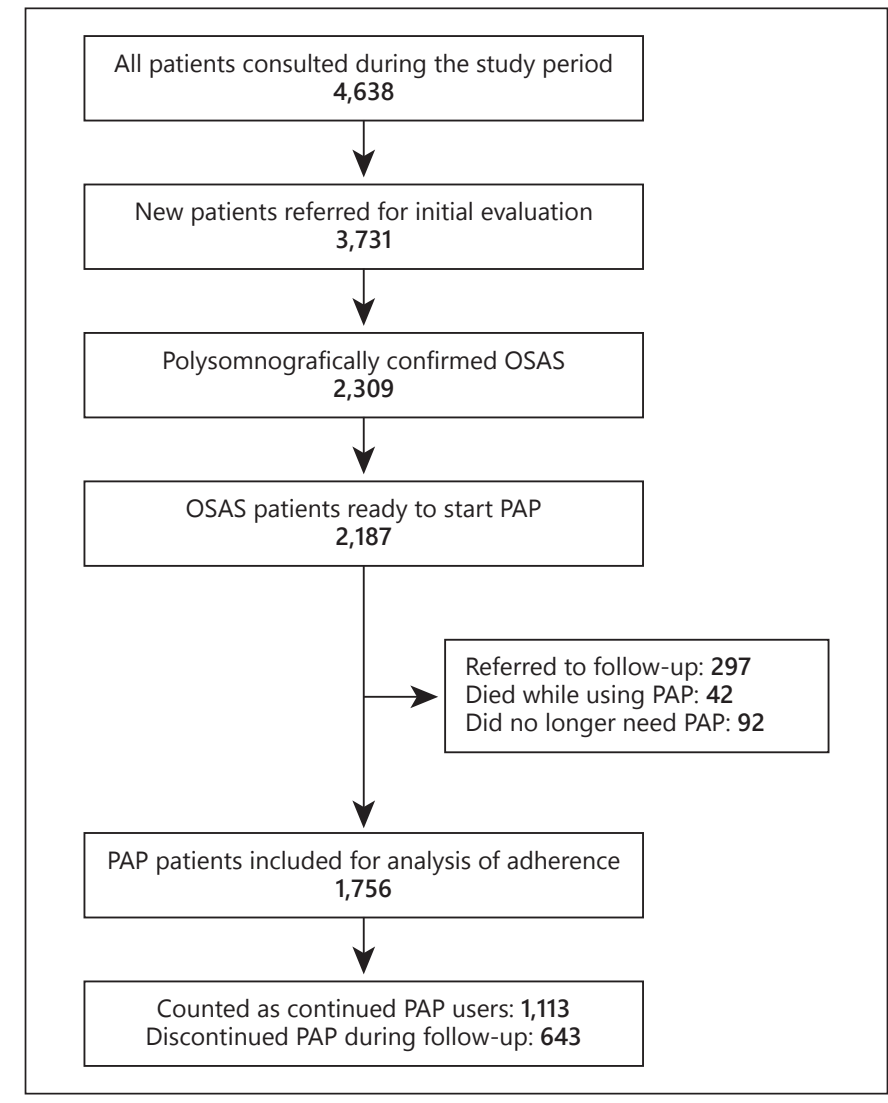

Fig. 1. Flow chart of patients exported from the electronic patient database of the sleep center St. Gallen, St. Gallen, Switzerland, November 2001 to November 2011.

Table 1. Baseline characteristics and polysomnographic findings of OSAS patients $(\mathrm{n}=1,756)$ started on PAP therapy at Kantonsspital St. Gallen, St. Gallen, Switzerland, November 2001 to November 2011

\begin{tabular}{lcc}
\hline & Median & IQR \\
\hline Age, years & 54 & $46-62$ \\
Gender & & \\
$\quad$ Male & 1,408 & \\
$\quad$ Female & 348 & \\
BMI at baseline & 30.4 & $27.2-34.9$ \\
ESS score at baseline & 11 & $7-15$ \\
\hline Time in bed, min & 362 & $359-370$ \\
Total sleep time, min & 304 & $263-333$ \\
\% sleep of time in bed & 84 & $73-91$ \\
AHI, events/h & 39.2 & $22-65$ \\
Arousal index, events/h & 54.5 & $38-76$ \\
SpO, \% & 92.9 & $91-94$ \\
ODI, events $/ \mathrm{h}$ & 25.3 & $11-49$ \\
\% time of $\mathrm{SpO} \mathrm{O}_{2}<90 \%$ & 21.9 & $4.3-74.6$ \\
REM sleep, min & 45 & $29-63$ \\
\hline
\end{tabular}

REM = Rapid eye movement. 
Fig. 2. Kaplan-Meier estimates for the adherence to PAP therapy in OSAS patients starting treatment between November 2001 and November 2011. The number of patients at risk, i.e., patients not lost through censoring or failure, is indicated at each time point. at risk:

1,756

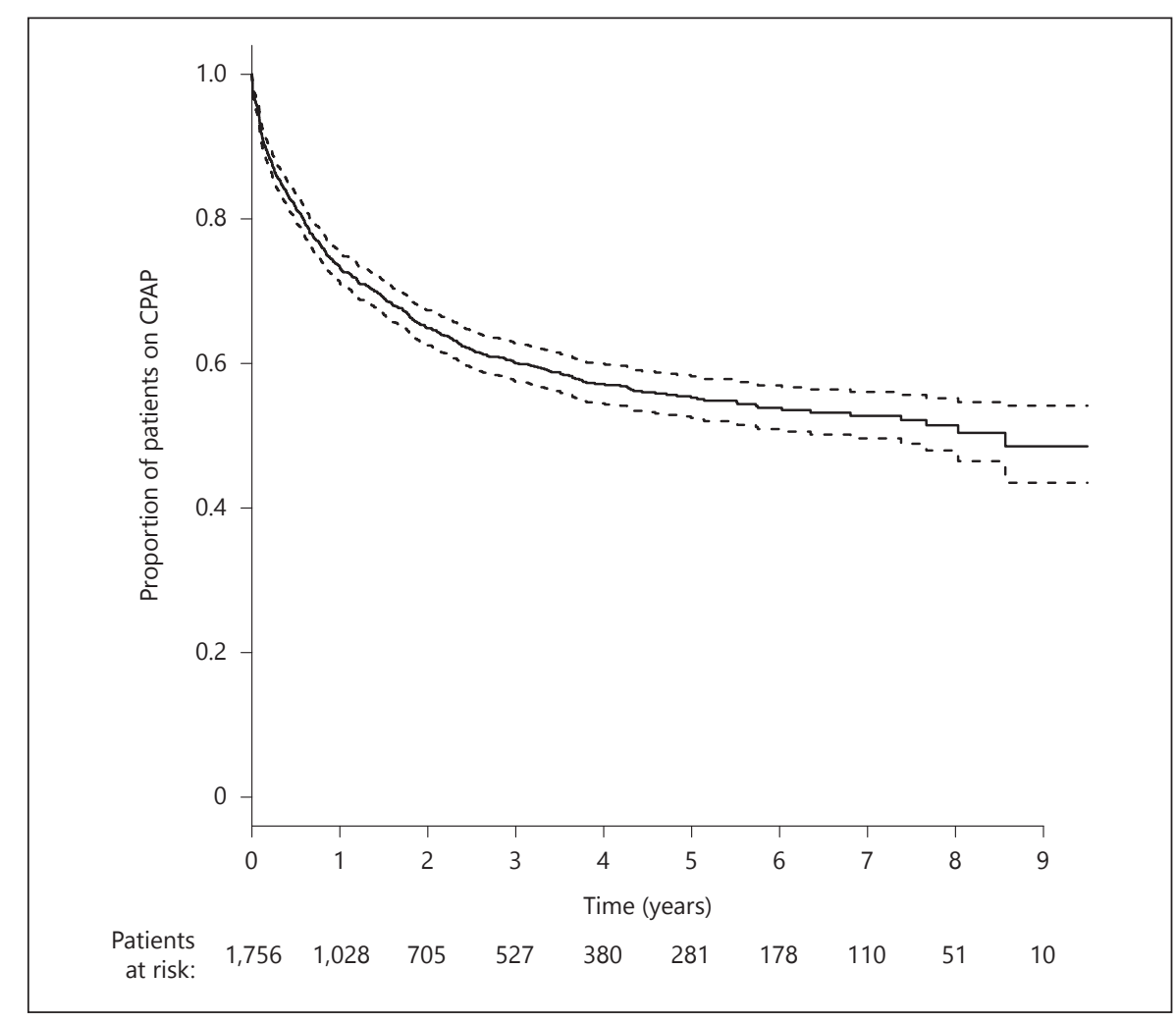

Table 2. Follow-up data of the most recent control of PAP therapy: clinical data, device information and pulse oximetry results

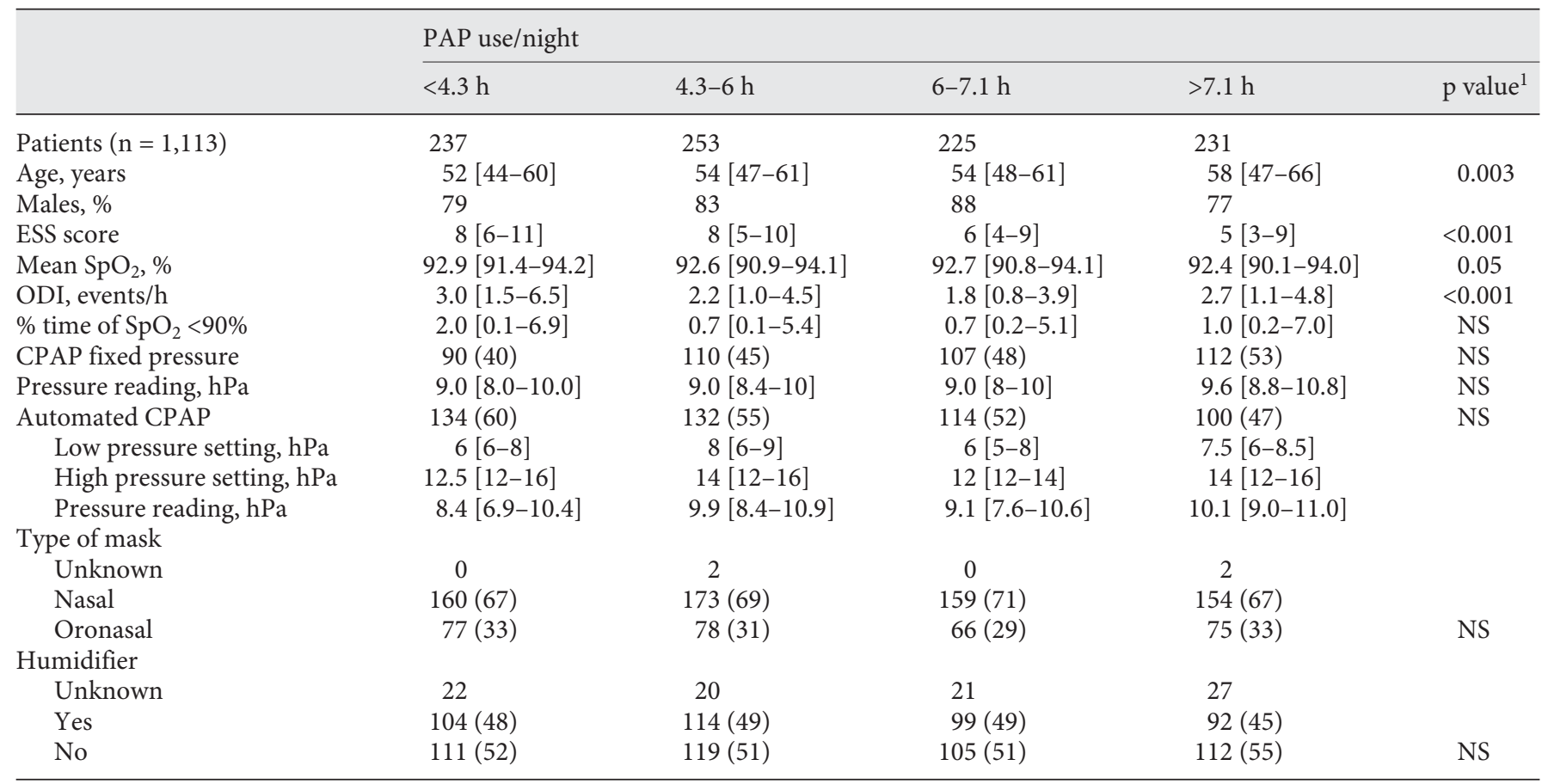

The data are spilt according to the quartiles of the average hours of CPAP use per night. Figures in parentheses are percentages; figures in brackets are IQRs. NS = Not significant.

${ }^{1}$ For categorical variables, $\chi^{2}$ tests were used; for continuous variables, Kruskal-Wallis tests are reported. 
Table 3. Predictors of adherence to PAP therapy in OSAS patients

\begin{tabular}{|c|c|c|c|c|c|c|c|}
\hline & Total & $\begin{array}{l}\text { Continued } \\
\text { PAP }\end{array}$ & $\begin{array}{l}\text { Discontinued } \\
\text { PAP }\end{array}$ & $\begin{array}{l}\text { Adjusted } \\
\mathrm{HR}\end{array}$ & $\begin{array}{l}\text { Lower } \\
95 \% \text { CI }\end{array}$ & $\begin{array}{l}\text { Higher } \\
95 \% \text { CI }\end{array}$ & $\begin{array}{l}\mathrm{p} \\
\text { (Wald test) }\end{array}$ \\
\hline Patients & 1,395 & 892 & $503(36)$ & & & & \\
\hline \multicolumn{8}{|l|}{ Gender } \\
\hline Male & 1,119 & 730 & $389(35)$ & & & & \\
\hline Female & 276 & 162 & $114(41)$ & 1.12 & 0.90 & 1.40 & NS \\
\hline \multicolumn{8}{|l|}{ Age } \\
\hline$<46.4$ years & 350 & 223 & $127(36)$ & & & & \\
\hline $46.4-54.3$ years & 364 & 235 & $129(35)$ & 0.99 & 0.77 & 1.27 & NS \\
\hline $54.3-61.7$ years & 350 & 220 & $130(37)$ & 1.12 & 0.87 & 1.43 & NS \\
\hline$>61.7$ years & 331 & 214 & $117(35)$ & 1.15 & 0.89 & 1.49 & NS \\
\hline \multicolumn{8}{|l|}{ ESS score } \\
\hline$<7$ & 396 & 226 & $170(43)$ & & & & \\
\hline $7-11$ & 326 & 211 & $115(35)$ & 0.79 & 0.62 & 1.00 & 0.050 \\
\hline $11-14$ & 318 & 227 & $91(29)$ & 0.60 & 0.47 & 0.78 & $<0.001$ \\
\hline \multirow{2}{*}{\multicolumn{8}{|c|}{$\mathrm{BMI}, \mathrm{kg} / \mathrm{m}^{2}$}} \\
\hline & & & & & & & \\
\hline$<27.4$ & 354 & 200 & $154(44)$ & & & & \\
\hline $27.4-30.5$ & 350 & 232 & $118(34)$ & 0.75 & 0.59 & 0.96 & 0.021 \\
\hline $30.5-35$ & 350 & 230 & $120(34)$ & 0.94 & 0.73 & 1.20 & NS \\
\hline$>35$ & 341 & 230 & $111(33)$ & 0.96 & 0.73 & 1.25 & NS \\
\hline \multicolumn{8}{|l|}{ ODI } \\
\hline$<11.8$ events/h & 368 & 178 & $190(52)$ & & & & \\
\hline $11.8-25.4$ events/h & 347 & 224 & $123(35)$ & 0.68 & 0.53 & 0.87 & 0.002 \\
\hline 25.4-50.4 events/h & 337 & 217 & $120(36)$ & 0.72 & 0.53 & 0.98 & 0.038 \\
\hline$>50.4$ events $/ \mathrm{h}$ & 343 & 273 & $70(20)$ & 0.50 & 0.32 & 0.77 & 0.002 \\
\hline \multicolumn{8}{|l|}{ AHI } \\
\hline$<22.8$ events/h & 354 & 179 & $175(49)$ & & & & \\
\hline $22.8-39.1$ events/h & 331 & 202 & $129(39)$ & 0.83 & 0.65 & 1.07 & NS \\
\hline $39.1-65.6$ events/h & 353 & 229 & $124(35)$ & 0.79 & 0.58 & 1.07 & NS \\
\hline$>65.6$ events $/ \mathrm{h}$ & 357 & 282 & $75(21)$ & 0.56 & 0.37 & 0.85 & 0.006 \\
\hline \multicolumn{8}{|c|}{ Multivariate statistics, continuous variables } \\
\hline Age & - & & & 1.01 & 0.997 & 1.014 & 0.19 \\
\hline Gender & - & & & 1.15 & 0.925 & 1.439 & 0.20 \\
\hline BMI & - & & & 1.00 & 0.987 & 1.018 & 0.69 \\
\hline ESS score & - & & & 0.98 & 0.966 & 1.002 & 0.077 \\
\hline ODI & - & & & 0.99 & 0.986 & 0.999 & 0.028 \\
\hline AHI & - & & & 0.99 & 0.985 & 0.997 & 0.003 \\
\hline
\end{tabular}

Only patients with complete data for the tested variables $(n=1,395)$ are included. Continuous variables were categorized according to the quartiles of their distribution. HRs and 95\% CIs for Cox proportional hazard regression adjusted for other variables (in quartiles and treated as continuous) are reported. Figures in parentheses are percentages. NS = Not significant. Italicized $\mathrm{p}$ values indicate $\leq 0.05$.

In a multivariate analysis treating all variables as continuous, ODI and AHI were significant independent predictors of adherence, while age, gender, BMI and ESS score were not (table 3 ).

\section{Adherence Evolution in Annual Cohorts}

The rate of PAP discontinuation was independent from the starting date in the period 2001 to 2009, with an average of $27 \%$ (95\% CI 25-30) of patients discontinuing within 1 year. A significant improvement in the 1-year adherence rate was observed for the 259 patients starting PAP over the last 2 years $(\mathrm{p}<0.001)$, with an average of $14 \%$ (CI 10-19) of patients discontinuing within 1 year (fig. 4). The difference for the last 2 years is also significant after adjustment for disease severity (AHI, ODI) by logistic regression. The absconder rate at 6 months was $20 \%$ (CI 18-22) for the first 8 years and improved to $10 \%$ (CI 7-15) for the last 2 years. 


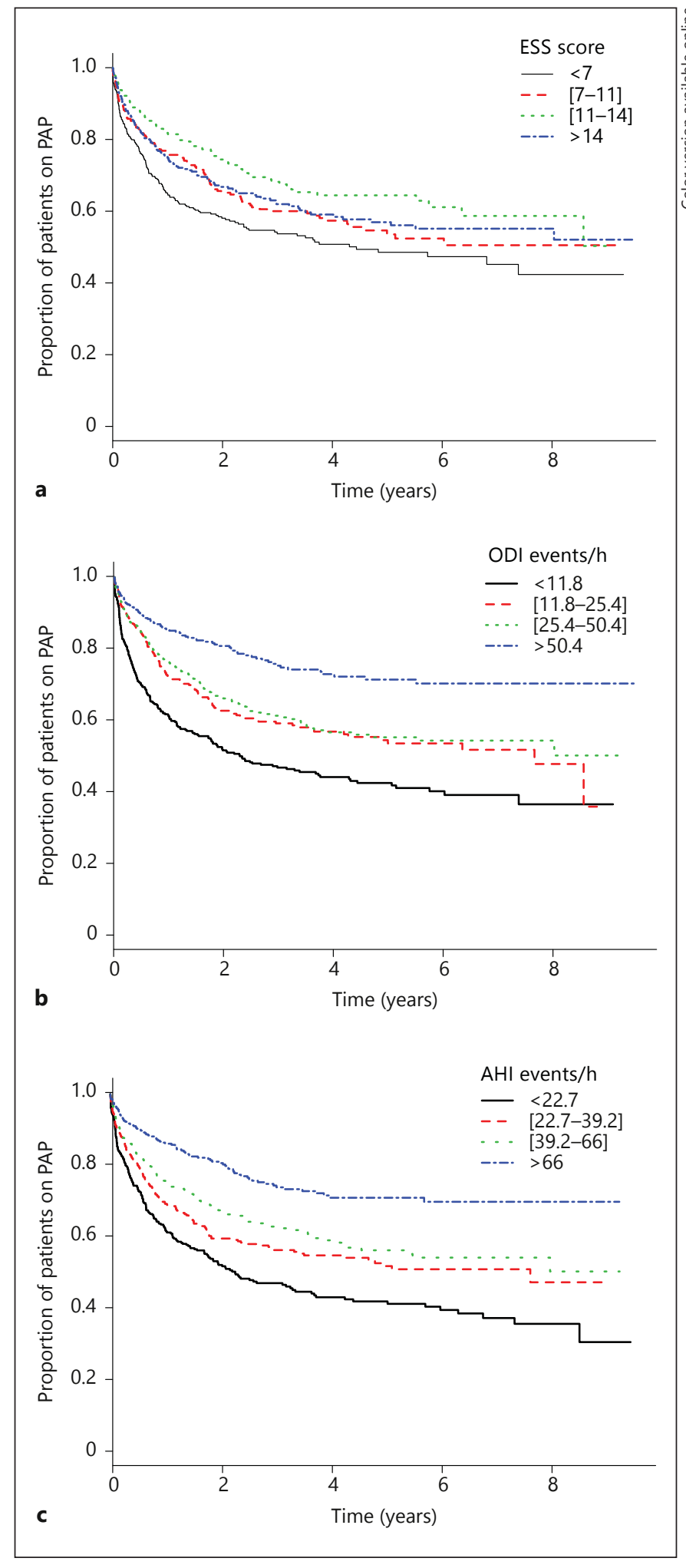

Fig. 3. Kaplan-Meier estimates for OSAS patients started on PAP therapy according to the quartiles of the ESS score (a), the ODI (b) and the AHI (c) in baseline PSG. Kantonsspital St. Gallen, St. Gallen, Switzerland, from November 2001 to November 2011.

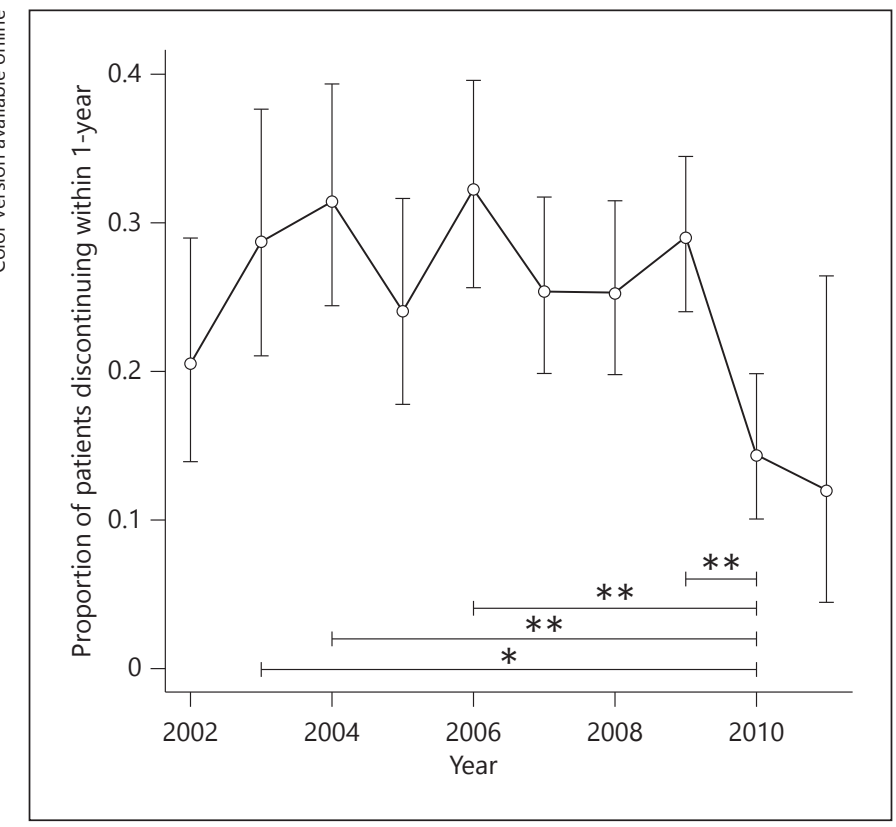

Fig. 4. Evolution of 1-year adherence over the 10-year time span of the study. Significance levels: ${ }^{*} 0.01<\mathrm{p}<0.05$; ${ }^{* *} 0.001<\mathrm{p}<$ 0.01 .

\section{Discussion}

The analysis of our large OSAS cohort resulted in an observed median adherence of 74,55 and $51 \%$ at 1,5 and 10 years, values considerably higher compared to most short-term treatment results reviewed in the Cochrane library [10] and somewhat higher than the results of a recently reported French cohort with 59\% of 1,141 PAPadherent patients after an average of 504 days of followup [15] and slightly below the $68 \%$ observed in 1,155 patients reported in 1999 [12]. The highest adherence rates were reported in a cohort of 639 patients treated in Oxford, UK, with a 5- and 10-year adherence of 81 and $70 \%$, respectively [13]. However, the Oxford cohort is considerably different, due to variations in the clinical algorithm followed. While in the UK only patients with a high ESS score were started on PAP, we followed a more liberal routine, allowing patients with low ESS scores for PAP. This is reflected by a large difference in the median ESS score of 15 (IQR 12-18) for the Oxford cohort, compared to a score of 11 (IQR 7-14) in our patients. The ODI of 28/h (IQR 14-48), measured with full-night pulse oxymetry, was also higher for the Oxford cohort, with 25/h of sleep (IQR 11-49) in our cohort. These differences in subjective and objective disease severity and methodological variations in the retrospective recruit- 
ment of charts explain the observed differences in adherence [13].

Differences in diagnostic and treatment algorithms may account for adherence variations in short-term cohorts. For example, a sleep specialist consultation prior to PSG, which was our routine practice, significantly improved 30-day adherence in a cohort of 403 OSAS patients treated in Chicago [16]. In line with previous reports [13], we also found that the likelihood to stop PAP is highest at the start of treatment and fades with the duration of treatment, approaching a very low absconder rate after 2-3 years. The PAP treatment in use at the last patient visit with a median PAP usage of $6 \mathrm{~h} /$ night and a median ODI of 2.5 events/h reflects an excellent correction of OSAS and is in line with the ESS score of 7, a normal value for German-speaking Swiss patients [14]. In our cohort, the use of treatment modifications aimed at increasing adherence was considerable, with half of the patients using automated pressure settings [17] and humidifiers.

As expected and reported previously [13, 15], age and gender were not related to adherence. Interestingly, we found that the correlation between the ESS score and the adherence rate is nonlinear, with the best adherence for ESS scores between 11 and 14. This is in line with previous studies $[13,15]$, where no linear correlation between ESS score and adherence was found. The observation of a nonlinear correlation leads to the hypothesis that very high ESS scores may be related to additional diseases, hindering the success of PAP, for example alcohol consumption, short sleep duration or psychiatric disorders. Objective measures of disease severity, as expected and reported previously for ODI [13] and AHI [15], are strong predictors of adherence. Overweight patients with a BMI between 27 and 30 were more likely to adhere to PAP than normal-weight and obese patients, an observation in line with a previous study, where a high BMI was related to non-adherence [15].

The 1-year adherence rate over the first 8 years was stable but improved significantly for the last 2 years. Possible reasons include a more stable management of the unit, an increased awareness for adherence targets in the nursing team, induced by the quality reassurance project of this study, and improvements in PAP materials. Many technical advances in machine design with new features, improved noise characteristics and comfortable masks were developed and introduced in Switzerland. In the last 2 years, the last generation of devices and masks were in use at our center.

Adherence to PAP for OSAS: 10-Year Results

\section{Limitations of the Study}

The study was performed with retrospectively collected data, and objective assessments of vigilance and sleep quality (attention tests or maintenance of wakefulness tests and follow-up PSG under CPAP) were not performed. However, a subjective measure of daytime sleep propensity (ESS) and objective measures of treatment quality (overnight pulse oximetry and device readouts of AHI) confirmed treatment success in an operational setting. Due to the characteristics of this retrospective study, it was not possible to weight the effect of variations in treatment settings (mask type, pressure levels, constant or fixed pressure), because all possible settings aimed at improving patient comfort were applied, and novel and innovative techniques were biased in patients difficult to treat. On the other hand, the study is likely to reflect the clinical routine in other OSAS treatment programs. The 1-year adherence rates reported here might serve as a measure for quality assurance to such programs.

\section{Conclusion}

In a large cohort of OSAS patients, we report treatment results for all patients diagnosed during the last 10 years. Given the relatively high long-term absconder rate of almost $50 \%$ at $5-10$ years, efforts to improve adherence should be intensified, especially at the beginning of treatment. Many patients that stopped PAP, although still likely to suffer from OSAS [18], could not be treated by alternative modalities and were lost to follow-up. Prospective studies on strategies to support such patients, likely to be affected with increased morbidity and mortality $[5,19]$, are needed.

\section{Acknowledgements}

The study was performed in the context of a quality reassurance program, which was jointly funded by equal unrestricted financial contributions of ResMed, Weinmann, Philips-Respironics and Pangas Switzerland. We thank Christian Ritz for his much appreciated statistical advice.

\section{Financial Disclosure and Conflict of Interest}

None of the coauthors has any conflicts of interest to declare. 


\section{References}

1 Young T, Palta M, Dempsey J, Skatrud J, Weber S, Badr S: The occurrence of sleep-disordered breathing among middle-aged adults. N Engl J Med 1993;328:1230-1235.

$\checkmark 2$ Antonopoulos CN, Sergentanis TN, Daskalopoulou SS, Petridou ET: Nasal continuous positive airway pressure (nCPAP) treatment for obstructive sleep apnea, road traffic accidents and driving simulator performance: a metaanalysis. Sleep Med Rev 2011;15:301-310.

-3 Sharma SK, Agrawal S, Damodaran D, Sreenivas V, Kadhiravan T, Lakshmy R, Jagia P, Kumar A: CPAP for the metabolic syndrome in patients with obstructive sleep apnea. N Engl J Med 2011;365:2277-2286.

-4 Peppard PE, Young T, Palta M, Skatrud J: Prospective study of the association between sleep-disordered breathing and hypertension. N Engl J Med 2000;342:1378-1384.

5 Marin JM, Carrizo SJ, Vicente E, Agusti AG: Long-term cardiovascular outcomes in men with obstructive sleep apnoea-hypopnoea with or without treatment with continuous positive airway pressure: an observational study. Lancet 2005;365:1046-1053.

6 Kirby T: Colin Sullivan: inventive pioneer of sleep medicine. Lancet 2011;377:1485.

7 Rapoport DM, Sorkin B, Garay SM, Goldring RM: Reversal of the 'Pickwickian syndrome' by long-term use of nocturnal nasal-airway pressure. N Engl J Med 1982;307:931-933.
8 Epstein LJ, Kristo D, Strollo PJ Jr, Friedman N, Malhotra A, Patil SP, Ramar K, Rogers R, Schwab RJ, Weaver EM, Weinstein MD: Clinical guideline for the evaluation, management and long-term care of obstructive sleep apnea in adults. J Clin Sleep Med 2009;5:263-276.

$\$ 9$ Giles TL, Lasserson TJ, Smith BH, White J, Wright J, Cates CJ: Continuous positive airways pressure for obstructive sleep apnoea in adults. Cochrane Database Syst Rev 2006; 3:CD001106.

10 Smith I, Nadig V, Lasserson TJ: Educational, supportive and behavioural interventions to improve usage of continuous positive airway pressure machines for adults with obstructive sleep apnoea. Cochrane Database Syst Rev 2009;2:CD007736.

11 Galetke W, Puzzo L, Priegnitz C, Anduleit N, Randerath WJ: Long-term therapy with continuous positive airway pressure in obstructive sleep apnea: adherence, side effects and predictors of withdrawal - a 'real-life' study. Respiration 2011;82:155-161.

12 McArdle N, Devereux G, Heidarnejad H, Engleman HM, Mackay TW, Douglas NJ: Longterm use of CPAP therapy for sleep apneal hypopnea syndrome. Am J Respir Crit Care Med 1999;159:1108-1114.

13 Kohler M, Smith D, Tippett V, Stradling JR: Predictors of long-term compliance with continuous positive airway pressure. Thorax 2010;65:829-832.

14 Bloch KE, Schoch OD, Zhang JN, Russi EW: German version of the Epworth Sleepiness Scale. Respiration 1999;66:440-447.
15 Gagnadoux F, Le VM, Goupil F, Pigeanne T, Chollet S, Masson P, Humeau MP, BizieuxThaminy A, Meslier N: Influence of marital status and employment status on long-term adherence with continuous positive airway pressure in sleep apnea patients. PLoS One 2011;6:e22503.

16 Pamidi S, Knutson KL, Ghods F, Mokhlesi B: The impact of sleep consultation prior to a diagnostic polysomnogram on continuous positive airway pressure adherence. Chest 2012; 141:51-57.

17 Randerath WJ, Schraeder O, Galetke W, Feldmeyer F, Ruhle KH: Autoadjusting CPAP therapy based on impedance efficacy, compliance and acceptance. Am J Respir Crit Care Med 2001;163:652-657.

18 Kohler M, Stoewhas AC, Ayers L, Senn O, Bloch KE, Russi EW, Stradling JR: Effects of continuous positive airway pressure therapy withdrawal in patients with obstructive sleep apnea: a randomized controlled trial. Am J Respir Crit Care Med 2011;184:1192-1199.

19 Martinez-Garcia MA, Campos-Rodriguez F, Catalan-Serra P, Soler-Cataluna JJ, AlmeidaGonzalez C, De la Cruz Moron I, Duran-Cantolla J, Montserrat JM: Cardiovascular mortality in obstructive sleep apnea in the elderly. Role of long-term CPAP treatment: a prospective observational trial. Am J Respir Crit Care Med 2012;186:909-916. 